factor in these various groups one is struck by the fact that in the majority of cases the ulnar nerve is unprotected by any bony parapet at the bend of the elbow, or so badly protected that during extension and flexion of that joint it is apt to slip in and out of its proper position. During flexion especially it may lie exposed to friction and pressure on the internal condyle. A consideration of many cases seems to justify the conclusion that movement, especially of a strenuous and frequently repeated character, is an important factor in the production of an interstitial neuritis. This moving contact with a bony surface is probably an important factor in producing the symptoms associated with a cervical rib, although $I$ do not think it has been shown that in the latter case the nervous tissue becomes surrounded by a definite thickening of connective tissue. In the case of the ulnar nerve, however, the nervous tissue $i$ constantly exposed to minor injuries, and the neuromatous condition so often found must be ascribed to chronic inflammation of traumatic origirn. It is a little difficult to understand why the flexed position of the elbow should in itself give rise to discomfort referred to the distribution of the ulnar nerve, as I believe there is no evidence to show that the nerve is stretched by that posture of the limb.

Finally, it would he instructive to leam the views of members of this Section in regard to the best procedure in connexion with these cases of traumatic neuritis. I have seen fairly good results from merely dividing the connective tissue strands by means of longitudinal incisions, but I have become still more impressed with the advantages of placing the nerve in front of the joint and so ensuring its complete relaxation. Possibly a combination of both measures may be the ideal treatment.

\section{HEREDITARY PERFORATING CLCER OF THE FOOT.}

BY E. P. HICKS, M.B. CAMB., M.R.C.S., D.T.M. \& H. LATE HOUSE PHYSICYAN TO ST. BARTHOLOMEW'S HOSPITAL.

IN November, 1920, a woman (15) ${ }^{1}$ came under my observation suffering from a perforating ulcer of the foot, a condition which she said was hereditary in her family. The following description is based chiefly on personal examination, partly on reference to hospital records.

The disease occurs in a family of which all the members were born in London and live in London, with two exceptions, one living at Exeter and the other in Canada. There are 34 members spread over four generations, including ten who suffer from the disease. The cardinal symptoms are perforating
Age of Onset. - The first symptoms appear in early adult life ; the ages recorded are "about 15 (?)," $22,24,31,33,35,36$.

sex.-There are four males and six females.

Etiology. - No cause is evident. The first sufferer was a doll-maker, and attributed his illness to his working in white lead. The disease is transmitted by both sexes.

Symptoms and Signs.- The first symptom counplained of in all cases but one is a corn, appearing first in the big toe. After a few months the thickened skin comes off and reveals an ulcer with indurated edges and purulent discharge. Soon this extends to the bone, and small pieces of bare bone are set free. There is usually no pain. Under treatment for some months the ulcer heals, but soon breaks down again, and so a process of ulceration and healing goes on for the rest of the patient's life. The process affects other toes and bones of the feet, and finally there is considerable deformity. The toes are shortened, and become flexible from loss of the phalanges, and are distorted from the normal position. In later stages the whole foot is described by relations as being shortened, but these patients are all dead, so that I have not seen them to verify the condition. Probably the tarsals and metatarsals are affected.

There is now a pause before the other symptoms appear. During this time there is little interference with the patient's life. Sometimes he suffers discomfort, or even actual pain, so that he is unable to walk about freely, but more often his life is quite normal except for the irksome necessity of repeated treatment to his feet. After an interval varying from a few months to several years, he suffers from shooting pains which may attack any part of the body. The legs and shoulders are most affected, and sometimes the head. Each pain is of very short duration, so that it has been diagnosed as the lightning pain of tabes dorsalis. The skin is tender to gentle pressure, but one patient (15) says that she obtains relief by firmly grasping and squeezing the affected area. The pain is often very severe. The children of the original sufferer (1) say that they knew when he was returning from work because they could hear his groans when he was still some distance away. At about the same time as the onset of the pains the patient begins to suffer from deafness. This is bilateral, and slowly progressive without remission, so that the patient is said to become finally completely deaf.

If the patient is examined a few years after the beginning of the disease the most striking feature is the ulceration of the foot. Its position may be on any of the toes, but most often on the great toe, and generally below the head of the metatarsal bone, or on its inner side. The ulcer has thickened irregular

Genearogical Table.

$1 m$

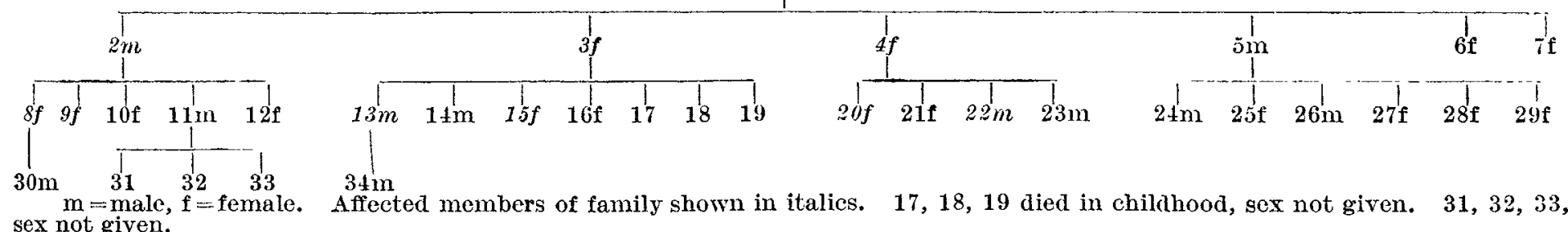
sex not given.

ulcers of the feet, shooting pains about the body, and deafness. The condition is very nearly similar in all the patients, so that it is easy to describe a common type of the disease. The affected members of the first and second generations are dead, and there are no medical records of the last years of their lives; those of the third generation have not yet progressed far, so that the picture of the later stages is not very definite. None of the fourth generation is affected, but they have not yet reached the age at which the disease appears.

Numbers in parentheses refer to the patient's number in the genealogical table. edges; the discharge is purulent; bare bone may be visible in its floor, or may be felt with a probe. The surrounding area is red and swollen, and swelling may extend up the lower part of the leg. The ulcer itself is painless, but suppuration may spread into the surrounding tissues, and these may be tender.

The reflexes of the lower limbs are lost. The ankle. jerks disappear first, later the knee-jerks. In no case which I have examined have I been able to obtain a plantar response. The abdominal reflexes are preserved, at any rate in the earlier stages. The reflexes of the arm are normal. The pupils always react to light and accommodation. 
The cranial nerves, with the exception of the auditory nerve, are normal. There is no nystagmus. The fundi are normal. The hearing of one patient (20)
has been examined by Mr. C. E. West, aural surgeon to St. Bartholomew's Hospital. He says that his findings were the same as in cases of primary cochlear degeneration. In another case (9), also examined at St. Bartholomew's Hospital, there was an accumu-
lation of wax sufficient to account for the deafness.

Sensation in the arms is normal. If the sensation of the feet and legs is tested when the acute condition has subsided definite changes are found. At first tactile sensation is lost over the first toe and interdigital cleft. The sensations of pain and heat and cold are lost over a rather larger area, so that there is definite dissociative anæsthesia. These changes must be confined to the feet for some years, because in only one of the patients I have examined has it been more extensive. This was a woman (9), who had first suffered from ulceration 17 years before. Loss of tactile sensation was confined to the anterior part of the feet, but loss of painful and thermal sensation extended up the lower part of the leg. Another woman (3) was examined in 1910, a year before her death and 24 years after the onset of the disease. Her notes record "loss of sensation to half-way up leg."

Ataxia was definitely absent in two cases (15 and $20)$; in one case (2) the notes state "gait is uncertain, but not typically ataxic." In the others there is no record. I found Rombergism in one case (9); it is noted as absent in three $(3,15$, and 20$)$; in another (2) the patient " is unable to stand with eyes shut and heels together." There was a slight deficiency of motor power in two cases ( 2 and 3 ), none in a third (15). The vesical and rectal control are normal. The Wassermann reaction of the blood has been taken in three cases. In two (3 and 24 ) it was negative, in one (15) it was first doubtful and later negative. In no case has the cerebro-spinal fluid been examined.

In the final stages ulceration and deformity of the foot gradually progress. The pain becomes very severe, deafness increases, and the patient is confined to bed. The death certificates of the four who have died are given below.

Prognosis.-The disease shortens life and curtails the activities of the sufferers during the last years of their life. Death took place at the ages of $51,46,46$, and 49. There seems to be no special risk of septicæmia.

Treatment has been unsatisfactory. Symptomatic treatment may relieve some of the suffering; for the ulcers rest is essential, and can only be obtained by keeping the patient in bed. It is difficult to devise anything which can be expected materially to affect the course of the disease.

Diagnosis. - I have been unable to reconcile the symptoms with those of any recognised hereditary nervous disease, or of any disease known to cause perforating ulcers. They bear some resemblance to those of syringomyelia, but I have been able to find no description of syringomyelia which exactly corresponds with them. It appears to be an instance of the condition to which Sir William Gowers ${ }^{1}$ gave the name "abiotrophy," and Raymond" referred to as "sénilité physiologique prématurée de certaines settled by post-mortem examination.

Hereditary and familial perforating ulcers of the feet have been recorded by Schultze, ${ }^{3}$ Goebell and Runge, ${ }^{4}$ and Bruns. ${ }^{5}$ Schultze described a family of three, a brother and two sisters, who suffered from perforating ulcers of the feet, with loss of knee- and ankle-jerks, and loss of sensation in the feet. There is no mention of deafness or shooting pains. He gave reasons for excluding tabes dorsalis, diabetes, polyneuritis, and leprosy. He discussed spina bifida occulta, and stated that he had observed it in several members of one family. Goebell and Runge described a family in which nine members in two generations suffered from perforating ulcers of the feet. They saw two of the sufferers, who had ulcers which discharged spicules of bone. Disturbances of sensation. were doubtful ; absence of glycosuria was noted in one case ; neither patient suffered from shooting pains: or deafness ; and in neither were the knee-jerks lost. Bruns's cases were familial. In a family of four boys. and a girl the eldest son escaped, but the other four children had perforating ulcers of the feet appearing. first at the age of 17. Again there is no mention of deafness.

\section{Conclusions.}

1. The disease is hereditary. Its main symptoms, are perforating ulcers of the feet, shooting pains in. various parts of the body, and deafness.

2 . It is progressive and shortens life.

3. It corresponds to no disease previously described, but bears some resemblance to syringomyelia.

Cases.

CASE 1.-Male, doll-maker; worked in white lead. His parents were free from ulcers, shooting pains, and deafness he himself suffered from ulcers of the feet, " rheumatism" (apparently shooting pains), and was very deaf. For some vears before his death his feet were shortened and his legs " mortified"; arms not affected. He died in 1874, aged 51. Death certificate : "Embolism and gangrene," according to his son's statement. This account is based on the statements of his descendants, as no hospital records are available.

CASE 2.-Male, brass-finisher. Symptoms began in 1885 at the age of 31 . He had ulcers in both feet, which repeatedly healed and broke down again; at the age of 35 the second toe of right foot was amputated. At the age of 44 part of the ungual phalanx of the left great toe was removed, owing to persistent ulceration. At this time he suffered from shooting pains in limbs; tactile sensation in limbs was fair, with 2 few patches of anæsthesia ; thermal anæsthesia noted in the legs. Tendon reflexes absent, eyes reacted to light and accommodation. Gait uncertain but not typically ataxic. He could not stand with eyes shut and heels together Quite deaf in both ears for 10 years and unable to hear watch placed close to ear or on mastoid process. He died in 1900, aged 46. Death certificate: "Tabes mesenterica."

CASE 3.-Female. In 1897, aged 33, began to suffer from shooting pains in the legs. Aged 39 , began to get deaf Aged 41 , perforating ulcers under each great toe noted. Pupils reacted to light and accommodation; loss of kneejerks ; anæsthesia in lower part of legs. Gait unsteady ; no Rombergism ; Wassermann reaction negative. Died at the age of 46. Death certificate: "Perforating ulcer of foot; syncope."

CASE 4.-Female. The disease began at age of $30:$ she suffered from ulcers of the feet, pain in the feet and head, and deafness. She died in 1905, aged 49. Death certificate: "Perforating ulcers of both feet, 15 years progressive necrosis of bones of both feet, softening of brain, and exhaustion." This account is based on the statements of her husband and children, as no hospital records are available.

CASE 8.-Female. From about the age of 15 had ulcers on the soles of the feet, which repeatedly healed and broke down again. In 1919, aged 32, she was admitted to hospital with ulceration of both big toes. Knee-jerks normal, pupils reacted normally, no glycosuria, Wassermann reaction negative, no spina bifida, no tabes. August, 1921, she wrote saying she still had ulcers of the feet, and now has also shooting pains and deafness.

CASE 9.-Female. In 1904, aged 22, first noticed ulceration of the feet. August, 1921 , right big toe showed evidence of old healed ulceration on the plantar surface; it was shorter than the left big toe. Knee- and ankle-jerks absent, supinator jerks natural, pupils reacted to light and accommodation, no nystagmus, slight Rombergism present. Sensation: tactile anæsthesia over first interdigital cleft in both feet; painful and thermal anæsthesia over lower parts of both legs. Ears : slightly deaf for two years; both ears found to be plugged with cerumen. She heard much better after this was removed. Auditory nerve not tested on account of recent removal of cerumen.

CASE 13.--Male, October 1921, aged 32, slightly deaf for some months. For two months has had black callosity below left big toe. No signs of inflammation; small patches of anæsthesia round both big toes, knee-jerks equal and normal, ankle-jerks absent.

CASE 15.-Female. In 1915, at the age of 21, symptoms first appeared. She had ulcers in both feet, with discharge of a small piece of bone on one occasion. Admitted to hospital. November, 1920. Nothing abnormal found in mouth, fauces, chest, and abdomen. In left foot, over heads of two inner metatarsal bones, were two ulcers; below the big toe the base of the second phalanx protruded and the bone was bare. There was swelling and cedema round the ulcers. Littles 
pain. Urine, no sugar. Nervous system : nothing abnormal found in cranial nerves, pupil reactions, and reflexes of arm. Epigastric reflexos equal, hypogastric obtained on left only. Knee-jerks brisk and equal. Ankle-jerks and plantar responses not obtained. Tactile sensation normal ; slight analgesia and confusion between heat and cold in feet only. No ataxia, no Rombergism. Wassermann reaction Dec. 7th, 1920, doubtful; Jan. 4th, 1921, negative. Discharged March 5th, 1921, with ulcers healed. Six weeks later recurrence of ulcer in left foot. Two pieces of bone dis-; charged from the big toe. No pain except "soreness" relieved after discharge of bone. She could walk well. Occasional shooting pains on outer side of right thigh and in left leg. August 18th, 1921, ulcer on outer side of fourth toe of right foot. Left foot healed. No change perceived in nervous system.

CASE 20.-Female. In 1920, aged 35, first had a corn below left great toe. No pain, no ulcer. In January, 1921, sharp intermittent pains in thighs, arms, and head; slight deafness began. August, 1921, thick black callosity on inner side of left big toe. No signs of inflammation. Tactile and painful sensation normal, definite slight loss of thermal sensation in both feet. Pupils reacted to light and accommodation. No nystagmus. Supinator jerks normal ; kneejerks equal and sluggish, ankle-jerks absent, plantar responses not obtained. No ataxia, no Rombergism. Aural condition investigated by Mr. O. E. West: deafness bilateral and constant, no tinnitus, both membranes lustrous and retracted, no opacities; right inferior turbinate large, otherwise nothing abnormal in nose. Tonsils normal, posterior nares could not be seen. Weber, not heard. Rinné, right, -35 secs. ; left, -30 secs. Findings analogous to those of primary cochlear degeneration.

CASE 22.-Male. In Canada. Letter received October, 1921. Then aged 38. For two years has had ulcers on both feet, healing and breaking down again, which incapacitate him from work but not from walking. No shooting pains. Gradually becoming deaf. Suffers from nasal catarrh and head noises.

I an indebted to Dr. J. H. Drysdale for permission to describe Case 15, and to Mr. West for permission to quote his findings in Case 20 .

References.-1. Gowers : Lectures on Diseases of the Nervous System, second series, No. 3. 2. Massalongo Les Maladies Nerveuses Familiales, Arch. Gen. de Med., 1909, p. 129. . Schultze : Familiär auftretendes beutsche Medizinische Wochenschrift, 1917, vol. xliii., p. 545 Extremitäten, Munch. med. Wochenschrift, 1914, p. 102. 5. Bruns: Familialer Symmetrischer Gangrän und Arthropathie an den Füssen, \&c.. Neurol. Centralblatt, 1903, vol xxii., p. 599 .

\section{EPIDIDYMTTIS AND SUPRAPLBIC PROSTATECTOMY. \\ A STUDY OF 50 CASES.}

By H. P. WINSBURY WHITE, M.B., CH.B., F.R.C.S. EDIN.,

LATE SENIOR HOUSE SURGEON, ST. PETER'S HOSPITAL FOR STONE AND OTHER URINARY DISEASES.

THE 50 cases are from a series of 55 consecutive cases operated upon at St. Peter's Hospital between April and October, 1921. On 5 of these cases, which died, the observations were incomplete, and therefore are not included. In order to determine accurately whether or not changes did occur in the epididymis as a result of prostatectomy, a careful note was made in each case of the existing condition of the scrotal contents before operation, and with a view to determining the significance of pre-existing venereal disease, and of previous catheterisations, facts relating to these points were also noted. These investigations show that inflammatory changes in the epididymis as a result of prostatectomy are the rule. Of the cases forming the subject of this paper 82 per cent. gave evidence of it. The degree of inflammatory process varied from the mildest form which could be detected by palpation, and caused no symptoms, to the purulent variety of epididymo-orchitis accompanied by local and constitutional disturbance.

Five degrees of inflammation were recognised and may be tabulated as follows from the mildest to the most severe form.

1. Thickening of the epididymis.

2. This change is more marked, the epididymis becomes adherent to the testis, and its coils adherent to one another.
3. The epididymis becomes large, hard, and firmly fixed to the testis, the change as a rule is more marked in the globus minor. There may be some tenderness. 4. The tunica vaginalis is distended with fluid. The epididymis is large, fixed, and tender ; pain is marked, tenderness is acute, the scrotum becomes red and sometimes cedematous.

5. The previous condition goes on to pus formation in the epididymis. It involves the testicle which sloughs.

The inflammation may be unilateral or bilateral, if the latter, it is generally more advanced on one side than on the other. In 58 per cent. the infection could be made out on one side only. The greater number of cases, 67 per cent, fell into one of the first three stages into which the epididymitis has been classified. The incidence of the acute cases is shown in the table for convenience in percentage form, although the number of cases is small.

Percentage of Cases of Different Degrees of Epididymitis following Prostatectomy.

\begin{tabular}{|c|c|c|c|c|c|c|}
\hline Group. & 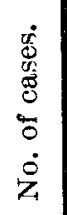 & 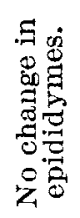 & 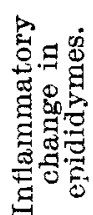 & 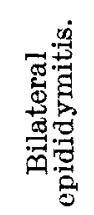 & 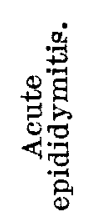 & 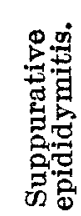 \\
\hline $\begin{array}{l}\text { 1. Fpididymes appar- } \\
\text { ently normal before } \\
\text { operation, previous } \\
\text { V.D. denied } \\
\text { 2. Signs of previous } \\
\text { infection of epidi- } \\
\text { dy mes, previous } \\
\text { V.D. denied } \\
\text { 3. History of } \nabla \text {. D., all } \\
\text { admitting gonor- } \\
\text { rhoea, and one case } \\
\text { syphilis also ; all } \\
\text { showing some sign } \\
\text { of previous epidi- } \\
\text { dymitis .. .. }\end{array}$ & 18 & 11 & 89 & 44 & 26 & 5 \\
\hline $\begin{array}{l}\text { 4. Total of three fore } \\
\text { going groups }\end{array}$ & 50 & 18 & 82 & 42 & 33 & 4 \\
\hline $\begin{array}{l}\text { 5. Patients whose pros- } \\
\text { tates were removed } \\
\text { in two stages }\end{array}$ & 9 & 44 & 56 & 22 & - & - \\
\hline
\end{tabular}

In all cases other than acute forms the patient complains of nothing in relation to the scrotal contents, and unless these are palpated from time to time during the convalescence, and the findings compared with those existing before operation, these changes may pass unnoticed; not until the tunica vaginalis is distended with fluid does the patient complain of testicular pain, so that quite marked changes may pass unrecognised. These milder forms generally reach their maximum about the end of the second week after operation, when subsidence begins. On the other hand, such a case may slowly progress to the acute stage, and even go on to pus formation in the third week or later; or later still, there may be recurring attacks of more or less acute epididymitis. But the condition may, and generally does, remain throughout in one of the earlier stages. The majority fall under one of the headings marked 2 and 3 of the classification of epididymitis.

Less Acute Variety.-The less acute forms of epididymitis are of interest because : (a) They may progress slowly to the acute stage; $(b)$ they may be the cause of recurrent attacks of epididymitis months later ; (c) they show the comparative frequence of infection of the epididymitis as a sequence of prostatectomy. Acute Variety.-This is of more serious import because : $(a)$ It is likely to prolong the convalescence of the patient; $(b)$ it is very likely to give rise to recurrent attacks of epididymitis later on ; $(c)$ it may progress to suppuration. When suppuration supervenes: (1) There is toxæmia; (2) the testicle is destroyed ; (3) pyæmia and death have been recorded. With regard to the mode of onset, two types have been observed-one developing rapidly and wellestablished by the end of the first week; the other 